\title{
Assessment of atrial regional and global electromechanical function by tissue velocity echocardiography: a feasibility study on healthy individuals
}

\author{
Miguel Quintana*1,2, Peter Lindell ${ }^{2}$, Samir K Saha1 ${ }^{1}$, Francesca del Furia1, \\ Britta Lind ${ }^{1}$, Satish Govind ${ }^{1}$ and Lars-Åke Brodin ${ }^{1}$
}

Address: ${ }^{1}$ Department of Clinical Physiology, Karolinska University Hospital, Huddinge. The Karolinska Institute, Stockholm, Sweden and ${ }^{2}$ Department of Cardiology, Karolinska University Hospital, Huddinge. The Karolinska Institute, Stockholm, Sweden

Email: Miguel Quintana* - miguel.quintana@labmed.ki.se; Peter Lindell - Peter.Lindell@karolinska.se;

Samir K Saha - Samir.Saha@karolinska.se; Francesca del Furia - francesca.delfuria@yahoo.com; Britta Lind - Britta.Lind@karolinska.se; Satish Govind - Satish.Govind@labmed.ki.se; Lars-Åke Brodin - lars-ake.brodin@labmed.ki.se

* Corresponding author

Published: 18 February 2005

Cardiovascular Ultrasound 2005, 3:4 doi:10.1 186/1476-7|20-3-4
Received: 21 January 2005

Accepted: 18 February 2005

This article is available from: http://www.cardiovascularultrasound.com/content/3/I/4

(C) 2005 Quintana et al; licensee BioMed Central Ltd.

This is an Open Access article distributed under the terms of the Creative Commons Attribution License (http://creativecommons.org/licenses/by/2.0), which permits unrestricted use, distribution, and reproduction in any medium, provided the original work is properly cited.

\begin{abstract}
Background: The appropriate evaluation of atrial electrical function is only possible by means of invasive electrophysiology techniques, which are expensive and therefore not suitable for widespread use. Mechanical atrial function is mainly determined from atrial volumes and volume-derived indices that are load-dependent, time-consuming and difficult to reproduce because they are observer-dependent.
\end{abstract}

Aims: To assess the feasibility of tissue velocity echocardiography (TVE) to evaluate atrial electromechanical function in young, healthy volunteers.

Subjects and methods: We studied 37 healthy individuals: 28 men and nine women with a mean age of 29 years (range 20-47). Standard two-dimensional (2-D) and Doppler echocardiograms with superimposed TVE images were performed. Standard echocardiographic images were digitized during three consecutive cardiac cycles in cine-loop format for off-line analysis. Several indices of regional atrial electrical and mechanical function were derived from both 2-D and TVE modalities.

Results: Some TVE-derived variables indirectly reflected the atrial electrical activation that follows the known activation process as revealed by invasive electrophysiology. Regionally, the atrium shows an upward movement of its walls at the region near the atrio-ventricular ring with a reduction of this movement towards the upper levels of the atrial walls. The atrial mechanical function as assessed by several TVE-derived indices was quite similar in all left atrium (LA) walls. However, all such indices were higher in the right (RA) than the LA. There were no correlations between the 2-D- and TVE-derived variables expressing atrial mechanical function. Values of measurement error and repeatability were good for atrial mechanical function, but only acceptable for atrial electrical function.

Conclusion: TVE may provide a simple, easy to obtain, reproducible, repeatable and potentially clinically useful tool for quantifying atrial electromechanical function. 


\section{Introduction}

The enlargement of left atrial (LA) diameter is associated with cardiovascular disease and is a risk factor for atrial fibrillation, stroke and death. [1-6] LA function reliably predicts exercise capacity in patients with recent myocardial infarction[7] or non-ischemic dilated cardiomyopathy[8] and differs in patients with ischemic and dilated cardiomyopathy.[9] Moreover, LA volume is an independent prognostic factor in several subsets of patients. [10-12] Although commonly used, LA size assessed by Mmode echocardiography does not correlate well with LA volumes, so several methods to estimate LA volumes have been developed.[13,14] The LA reservoir, conduit and pump functions may be estimated from volume measurements. [15-19] However, the reliability and clinical usefulness of those methods have been poorly studied. Pulsed-wave Doppler interrogation of the blood flow velocity during atrial contraction, the peak mitral inflow A wave, and its velocity time integral have also been used as surrogate markers of atrial function. [20-22] These variables represent the diastolic properties of the LV [23-25] and do not accurately reflect atrial mechanical properties. Tissue velocity echocardiography (TVE) has now been developed as a valuable tool for the evaluation of left and right ventricular systolic and diastolic functions.[26,27] Furthermore, this technique has also been used to assess the regional functions of the left and right atrium.[28,29] Although atrial anatomy was described more than a century ago, a new interest in atrial anatomy and its relations with atrial electromechanical function has only recently emerged.[30,31] Conventionally, atrial electrical function has been evaluated from resting electrocardiography (ECG), and more accurately by invasive electrophysiology techniques. [32-34] The rapid development of these invasive techniques has improved not only diagnostic capabilities,[35,36] but also our understanding of how the electrical impulse spreads through atrial tissues, $[37,38]$ and has led to improvements in the treatment of supraventricular tachy-arrhythmias. [38-40] However, the invasive nature and the high costs of these procedures limit their widespread use and repeatability. Therefore, the development of noninvasive, safe, accurate and repeatable methods that might provide similar information is necessary. We aimed here to find simple and repeatable methods to assess both electrical and mechanical regional atrial functions by means of TVE.

\section{Methods}

\section{Population}

We studied 37 healthy individuals: 28 men and nine women with a mean age of 29 years (range 20-47). The individuals were recruited from among hospital employees, cardiovascular technicians and medical students. None showed symptoms of cardiovascular disorders or were receiving pharmacological cardiovascular agents. All had normal standard two-dimensional (2-D) and Doppler echocardiograms. All subjects were on sinus rhythm and none hade $\mathrm{A}-\mathrm{V}$ or intra-ventricular conduction defects. The Ethical Committee at the Karolinska University Hospital, Huddinge, approved the study. All individuals received written information and gave informed consent.

\section{Echocardiography}

A standard 2-D and Doppler echocardiogram with superimposed TVE images was performed using a $3.5 \mathrm{MHz}$ transducer with commercially available equipment (System FiVe ${ }^{\mathrm{TM}}$, GE Vingmed, Horton, Norway). Standard parasternal short- and long-axis views as well as apical 2-, 3and 4-chamber views acquired at expiratory apnea with at least 90 frames per second were digitized during three consecutive cardiac cycles in cine-loop format for off-line analysis.

\section{Off-line analyses}

All echocardiographic images were analyzed off-line using software (Echopac ${ }^{\mathrm{TM}}$ 6.3.4, GE Vingmed) for the calculation of standard 2-D and Doppler echocardiography as well as for the analysis of TVE variables.

\section{Standard 2-D and Doppler echocardiography}

Measurements of the left ventricular (LV) function comprised septum and posterior wall thickness; LV end-systolic and diastolic dimensions; LV fractional shortening, and LV ejection fraction (LVEF) according to international standards.[41] Measurements of atrial function comprised left atrial (LA) diameter measured from the parasternal long axis; right atrium (RA) and LA long and short axes; LA and RA maximal volume; LA and RA minimal volume, and RA and LA volumes at the beginning of the P-wave measured from the apical 4- and 2-chamber views. LA and RA ejection fractions were measured according to the formula: (maximal volume-minimal volume)/ maximal volume. LA and RA active emptying values were calculated as (volume at P-wave-minimal volume)/volume at P-wave. $[8,9,42]$

\section{Tissue velocity echocardiography}

The RV and LV long axis functions were assessed from apical views. Six basal LV segments were identified as follows: the RV free wall; the LV postero-septal wall, and the LV lateral wall from the apical 4-chamber view; the LV inferior and anterior walls from the apical 2-chamber view, and the LV posterior wall from the apical 3-chamber view. A sample volume was positioned at the base of each ventricular wall excluding the A-V plane during the entire heart cycle to obtain a tissue velocity profile during three consecutive cardiac cycles. Both systolic and diastolic phases of the velocity profile were considered and the following parameters were analyzed (upper part of Fig. 1): 

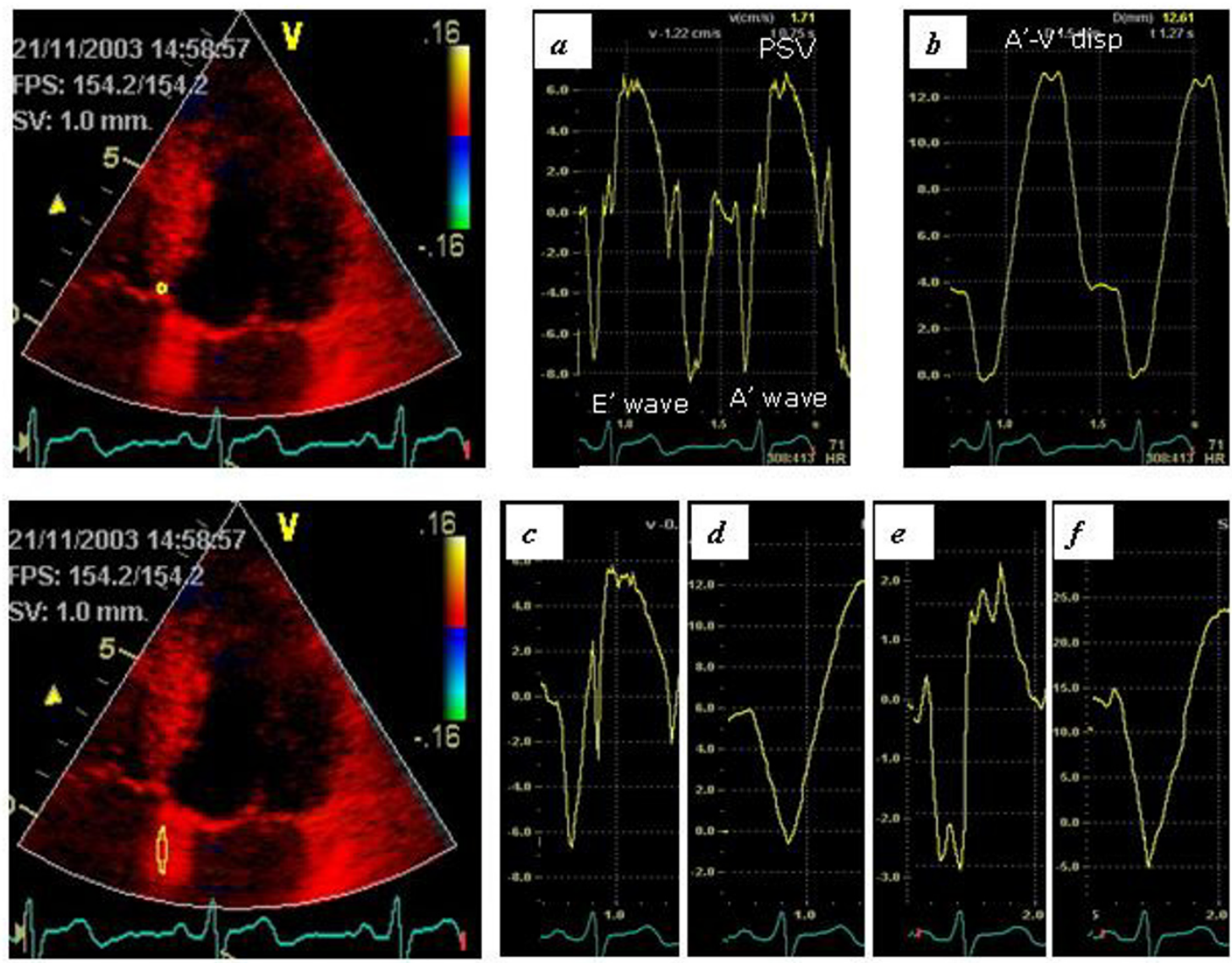

\section{Figure I}

Assessment of atrial and ventricular mechanical function. The upper panel shows the systolic and diastolic velocities (a) and the A-V place displacement (b) measured at the basal level of the inter ventricular septum. The lower panel shows the atrial velocity $(c)$, atrial displacement (d), atrial strain rate (e) and atrial strain (f) measured at the inter atrial septum below the mitral ring.

peak systolic velocity (PSV, in centimeters per second), measured at the peak velocity during the ejection period; peak velocity at early diastole (E'-wave, in centimeters per second), measured at the peak velocity at early diastole, and peak velocity at late diastole (A'-wave, in centimeters per second), measured at the peak velocity at late diastole. The atrio-ventricular myocardial wall displacement ( $\mathrm{A}^{\prime}-\mathrm{V}^{\prime}$ disp., in millimeters) in the long axis was obtained by automated temporal integration of the PSV of the basal segments during the ejection period.

The different atrial walls were identified from the same apical views as follows: the right atrial wall (RA), the interatrial septum (IAS), and the left atrial lateral wall (LA-Lat) from the apical 4-chamber view; the left atrial inferior wall
(LA-Inf) and the left atrial anterior wall (LA-Ant) from the apical 2-chamber view; and the left atrial posterior wall (LA-Post) from the apical 3-chamber view. Each atrial wall was studied at low and mid levels, placing a $2 \mathrm{~mm}$ sample volume at low atrial walls excluding the A-V plane during the entire cardiac cycle and at the mid portion of each atrial wall. The regional electromechanical function at each atrial wall was studied by the following time intervals (Figure 2). The PA-start interval (P-Aa' start) was defined as the time between the beginning of the P-wave on the monitor's ECG to the start of the $\mathrm{A}^{\prime}$ wave on the TVE-curve profile. The PA-peak interval (P-Aa' peak) was the time between the beginning of the P-wave on the monitor's ECG to the peak of the $\mathrm{A}^{\prime}$ wave on the TVEcurve profile. The A-wave duration (Aa'-dur.) was the time 


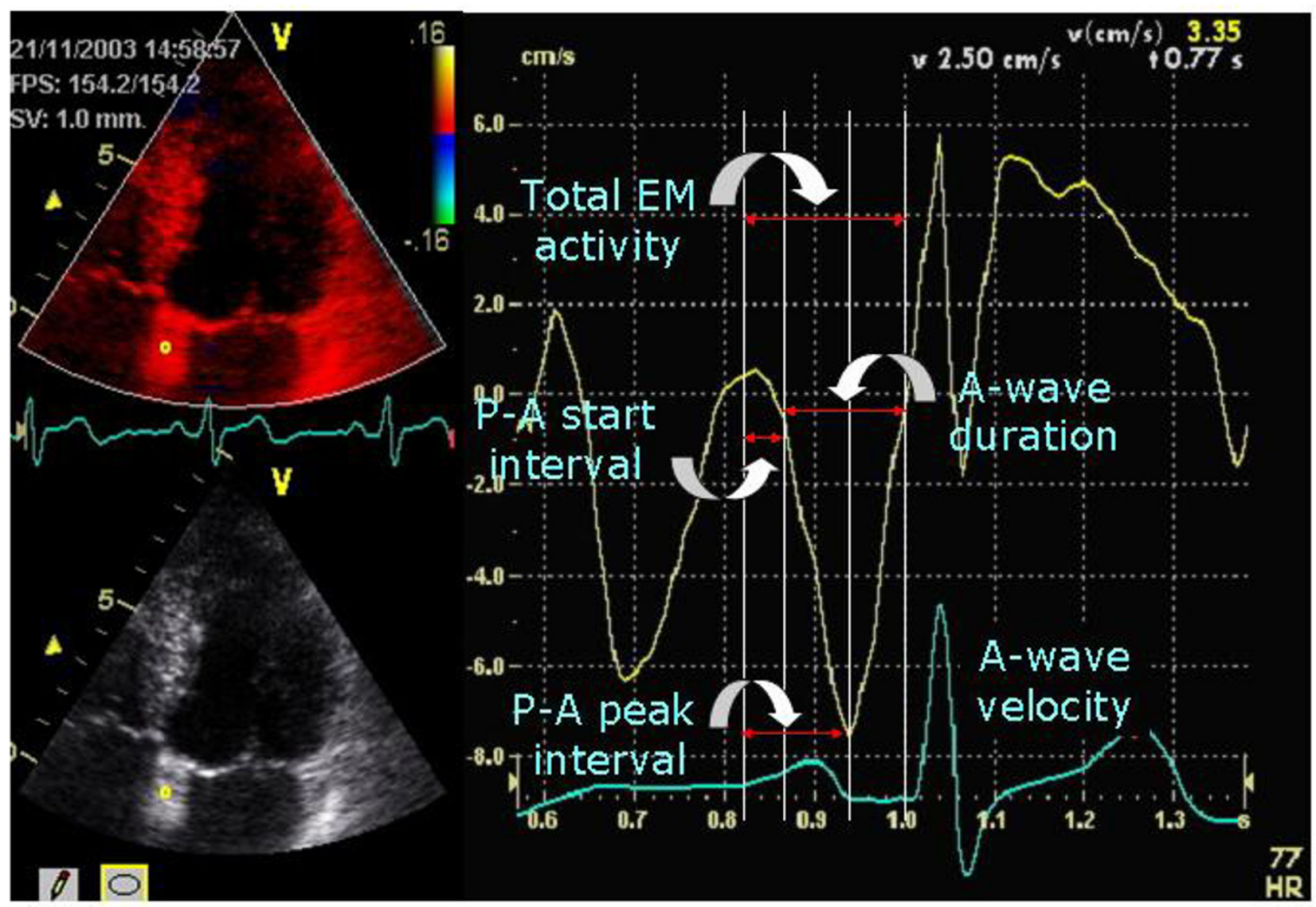

Figure 2

Assessment of some time intervals and $\mathrm{Aa}^{\prime}$ wave velocity at the low level of the inter atrial septum

from the beginning to the end of the A'-wave on the TVEcurve profile. The total electromechanical activity (TEMA) was the time between the beginnings of the P-wave on the monitor ECG to the end of the $\mathrm{A}^{\prime}$ wave on the TVE-curve profile.

The regional mechanical function of each atrial wall was assessed by the peak velocity during atrial contraction (Aa' peak vel.), the atrial displacement occurring during atrial contraction (Aa' disp.) and the ratio of atrial displacement measured at atrial level to the total LV myocardial displacement measured at ventricular level (Aa' cont.) (lower part of Figure 1). In addition, strain rate (Aa' SR) and strain (Aa' S) were assessed in each low atrial wall using a sample volume of $12 \mathrm{~mm}$.

\section{Statistical analyses}

Data are presented as means \pm standard deviations (SD). Analysis of variance (ANOVA) with repeated measures was used to test statistical significance of the studied variables at different atrial and ventricular walls. When ANOVA showed statistically significant differences among atrial and ventricular walls, post hoc analysis with Bonferroni's test was performed to assess differences among those walls. Correlation coefficients were calculated to assess the relationship among several markers of atrial mechanical function. The inter- and intra-observer repeatability and measurement errors for variables reflecting the atrial electromechanical function were assessed by the coefficient of variation and by the British Standards Institution method, the value below which the difference 
Table I: Demographic features and resting echocardiographic data. Numbers are means \pm SD.

\begin{tabular}{|c|c|c|c|}
\hline Age, years & $29 \pm 7$ & & \\
\hline Gender (M/F) & $28 / 9$ & & \\
\hline Height, cm & $175 \pm 8$ & & \\
\hline Weight, kg & $76 \pm 14$ & & \\
\hline Heart rate, bpm & $66 \pm 12$ & & \\
\hline $\mathrm{P}-\mathrm{Q}$ time, $\mathrm{ms}$ & $166 \pm 16$ & & \\
\hline LA diameter, $\mathrm{mm} / \mathrm{m}^{2}$ & $18.9 \pm 1.5$ & & \\
\hline Septal wall thickness, mm & $9.6 \pm 1.1$ & & \\
\hline Posterior wall thickness, $\mathrm{mm}$ & $9.5 \pm 1.2$ & & \\
\hline $\mathrm{LV}$ end diastolic diameter, $\mathrm{mm} / \mathrm{m}^{2}$ & $26.5 \pm 2.3$ & & \\
\hline LV fractional shortening, \% & $35 \pm 6$ & & \\
\hline LV ejection fraction, \% & $72 \pm 8$ & & \\
\hline E-wave, $\mathrm{cm}$ & $90 \pm 17$ & & \\
\hline A-wave, $\mathrm{cm}$ & $56 \pm 12$ & & \\
\hline E/A ratio & $1.68 \pm 0.45$ & & \\
\hline LA long axis, $\mathrm{mm} / \mathrm{m}^{2}$ & $26 \pm 2$ & $\mathrm{RA}$ long axis, $\mathrm{mm} / \mathrm{m}^{2}$ & $25 \pm 3$ \\
\hline LA short axis, $\mathrm{mm} / \mathrm{m}^{2}$ & $21 \pm 3$ & $\mathrm{RA}$ short axis, $\mathrm{mm} / \mathrm{m}^{2}$ & $22 \pm 2$ \\
\hline LA maximal volume, $\mathrm{ml} / \mathrm{m}^{2}$ & $29 \pm 5$ & $\mathrm{RA}$ maximal volume, $\mathrm{ml} / \mathrm{m}^{2}$ & $31 \pm 7$ \\
\hline LA minimal volume, $\mathrm{ml} / \mathrm{m}^{2}$ & $15 \pm 3$ & $\mathrm{RA}$ minimal volume, $\mathrm{ml} / \mathrm{m}^{2}$ & $17 \pm 4$ \\
\hline LA P-wave volume, $\mathrm{ml} / \mathrm{m}^{2}$ & $18 \pm 4$ & RA P-wave volume, $\mathrm{ml} / \mathrm{m}^{2}$ & $19 \pm 5$ \\
\hline LA ejection fraction, \% & $49 \pm 9$ & RA ejection fraction, $\%$ & $46 \pm 10$ \\
\hline LA active emptying, $\%$ & $17 \pm 7$ & RA active emptying, $\%$ & $15 \pm 9$ \\
\hline
\end{tabular}

Table 2: Systolic and diastolic myocardial velocities measured at different right and left ventricular walls

\begin{tabular}{|c|c|c|c|c|c|c|}
\hline \multirow[t]{2}{*}{ Variable } & \multicolumn{6}{|c|}{ Ventricular walls } \\
\hline & RV & Post-sep & Lateral & Inferior & Anterior & Posterior \\
\hline PSV, cm/s & $10.5 \pm 1.3$ & $6.8 \pm 0.9$ & $8.5 \pm 1.8$ & $7.5 \pm 1.1$ & $7.9 \pm 1.6$ & $7.6 \pm 1.3$ \\
\hline E'-wave, $\mathrm{cm} / \mathrm{s}$ & $10.2 \pm 2.3$ & $9.9 \pm 1.1$ & $12.2 \pm 1.5$ & $10.6 \pm 2.1$ & $10.1 \pm 2.1$ & $12.4 \pm 1.9$ \\
\hline$A^{\prime}$-wave, $\mathrm{cm} / \mathrm{s}$ & $8.4 \pm 2.8$ & $5.9 \pm 1.3$ & $4.7 \pm 1.5$ & $6.3 \pm 2.0$ & $4.7 \pm 1.7$ & $6.1 \pm 2.1$ \\
\hline E'/A' ratio & $1.2 \pm 0.1$ & $1.7 \pm 0.1$ & $2.6 \pm 0.1$ & $1.7 \pm 0.2$ & $2.1 \pm 0.2$ & $2.0 \pm 0.1$ \\
\hline$A^{\prime}-V^{\prime}$ disp., mm & $21.5 \pm 3.5$ & $13.6 \pm 1.5$ & $13.7 \pm 2.0$ & $15.3 \pm 1.6$ & $13.7 \pm 1.9$ & $15.4 \pm 1.8$ \\
\hline Atrial disp., mm & $5.8 \pm 2.2$ & $4.1 \pm 1.3$ & $2.5 \pm 0.8$ & $3.8 \pm 1.5$ & $2.9 \pm 0.9$ & $3.0 \pm 1.1$ \\
\hline Atrial cont., \% & $27 \pm 8$ & $30 \pm 9$ & $19 \pm 7$ & $25 \pm 9$ & $22 \pm 8$ & $20 \pm 6$ \\
\hline
\end{tabular}

Abbreviations: cont., contribution; disp., displacement; PSV, peak systolic velocity

between two measurements will lie with a probability of 0.95. $P<0.05$ was considered statistically significant.

\section{Results}

All demographic features and measures of standard 2-D and pulsed-wave Doppler echocardiography data are shown in Table 1. Of interest, no differences were found between measures of RA and LA functions, as assessed by short or long axes, or among volumes and volumederived indices. TVE-derived variables assessing the RV and LV long-axis systolic and diastolic functions are shown in Table 2. No significant differences among LV walls were found for any index of systolic and diastolic function. TVE-derived variables obtained from the RV free wall were significantly different from each LV wall.

Table 3 shows several time intervals. The PA-start interval (P-Aa' start) was longer at low atrial levels in each atrial wall than at the mid atrial level and shorter at the RA than for all LA walls (Fig. 3). Some statistical significant differences among different LA walls were also found. The PApeak interval (P-Aa' peak) was similar at low and mid atrial 
Table 3: Time intervals expressed in milliseconds measured at low and mid atrial levels in the myocardial walls of the RA and LA.

\begin{tabular}{|c|c|c|c|c|c|c|c|c|}
\hline Variables & Level & RA & IAS & LA-Lat & LA-Inf & LA-Ant & LA-Post & $P *$ \\
\hline P-Aa' start & Low & $51 \pm 11$ & $59 \pm 9$ & $69 \pm 11$ & $62 \pm 10$ & $70 \pm 10$ & $62 \pm 11$ & $<0.001$ \\
\hline \multirow[t]{2}{*}{ (ms) } & Mid & $38 \pm 9$ & $47 \pm 8$ & $57 \pm 9$ & $51 \pm 11$ & $59 \pm 10$ & $52 \pm 11$ & $<0.001$ \\
\hline & $P$ & $<0.001$ & $<0.001$ & $<0.001$ & $<0.001$ & $<0.001$ & $<0.001$ & \\
\hline P-Aa' peak & Low & $117 \pm 22$ & $108 \pm 14$ & $119 \pm 14$ & $108 \pm 12$ & $123 \pm 14$ & $107 \pm 11$ & $<0.001$ \\
\hline \multirow[t]{2}{*}{ (ms) } & Mid & $110 \pm 20$ & $104 \pm 15$ & $115 \pm 15$ & $98 \pm 17$ & $123 \pm 16$ & $99 \pm 17$ & $<0.01$ \\
\hline & $P$ & 0.06 & 0.04 & 0.1 & $<0.001$ & 0.9 & $<0.001$ & \\
\hline Aa'-dur. & Low & $135 \pm 16$ & $120 \pm 16$ & $106 \pm 10$ & $118 \pm 13$ & $113 \pm 12$ & $112 \pm 12$ & $<0.001$ \\
\hline \multirow[t]{2}{*}{ (ms) } & Mid & $145 \pm 19$ & $127 \pm 16$ & $117 \pm 10$ & $115 \pm 12$ & $121 \pm 16$ & $115 \pm 12$ & $<0.01$ \\
\hline & $P$ & $<0.001$ & $<0.001$ & $<0.001$ & 0.1 & $<0.001$ & 0.07 & \\
\hline TEMA & Low & $186 \pm 17$ & $179 \pm 18$ & $175 \pm 15$ & $179 \pm 15$ & $183 \pm 14$ & $174 \pm 12$ & 0.07 \\
\hline \multirow[t]{2}{*}{ (ms) } & Mid & $183 \pm 21$ & $174 \pm 16$ & $173 \pm 15$ & $175 \pm 15$ & $180 \pm 19$ & $167 \pm 17$ & 0.2 \\
\hline & $P$ & 0.3 & 0.1 & 0.5 & 0.1 & 0.3 & 0.06 & \\
\hline
\end{tabular}

Abbreviations: Aa'-dur., duration of the A wave; IAS, inter-atrial septum; LA-Ant, left atrial anterior wall; LA-Inf, inferior left atrial wall; LA-Lat, left lateral atrial wall; LA-Post, left posterior atrial wall; ms, milliseconds; $\mathbf{P}$, by paired $t$ test; $\boldsymbol{P} *$, by analysis of variance; $\mathrm{P}$-Aa' start, time from the beginning of the $\mathrm{P}$-wave to the start of the A-wave; $\mathrm{P}$-Aa' peak, time from the beginning of the $\mathrm{P}$-wave to the peak of the $\mathrm{A}$-wave; $\mathrm{RA}$, right atrial wall; TEMA, total electromechanical activity.

P-Aa' start Low: RA vs all LA-walls $(P<0.00$ I $)$, IAS and LA-Inf vs LA-Lat $(P<0.00$ I $)$

P-Aa' start Mid: RA vs all LA-walls $(P<0.0$ I), IAS vs LA-Lat and LA-Ant $(P<0.00$ I $)$; LA-Inf vs LA-Lat and LA-Inf $(P<0.00$ I $)$; LA-Post vs LA-Ant $(P$ $<0.01$ )

P-A'a peak Low and Mid: IAS, LA-Inf and LA-Post vs LA-Lat and LA-Ant $(P<0.00$ I for all comparisons)

Aa' dur. Low: RA, IAS and LA-Inf vs LA-Lat $(P<0.00 I)$

Aa' dur. Mid: RA vs all walls $(P<0.00 I)$, IAS vs LA-Lat, LA-Inf and LA-Post $(P<00 \mathrm{I})$

TEMA Low: RA vs LA-Lat, LA-Inf and LA-Post $(P<0.00 I)$. No differences among all LA-walls.

TEMA Mid: RA vs LA-Lat, LA-Inf, LA-Post $(P<0.00 \mathrm{I})$, LA-Ant vs LA-Inf and LA-Post $(P<0.00 \mathrm{I})$

levels in almost all atrial walls with exceptions in the inferior and posterior LA walls. This interval was shorter for the IAS, inferior and posterior LA walls than for the lateral and anterior LA walls at mid and low levels (Fig. 4). The A-wave duration (Aa'-dur.) was shorter at the low atrial level than at the mid atrial level in each atrial wall, but not in the inferior and posterior LA walls. The total electromechanical activity (TEMA) was similar in all RA and LA atrial walls measured at low and mid levels, and no differences were found between any of the LA walls.

Table 4 shows several velocities and velocity-derived variables: The peak velocity during atrial contraction (Aa' peak vel.) was higher at low than mid levels in each atrial wall, but no significant differences were found between any LA walls. This variable was higher in RA than in all LA walls. Similar results were found for the atrial displacement occurring during atrial contraction (Aa' disp.) and the ratio of atrial displacement measured at atrial level to the total LV myocardial displacement measured at ventricular level (Aa' cont.). The strain rate (Aa' SR) was higher in the RA than in all LAwalls, and lower in the IAS than in the lateral and posterior LA walls. The strain (Aa' S) was higher in the RA than in all LA-walls, and no differences were found between LA walls.

Tables 5 and 6 show the correlation coefficients between 2-D-derived and TVE-derived variables of LA and RA glo- bal mechanical function. There were no correlations between 2-D- and TVE-derived variables, apart from modest correlations between LA diameter and LA displacement, between RA long axis diameter and RA displacements, and between RA ejection fraction and strain rate.

The inter- and intra-observer measurement error and repeatability, as expressed by the British Standards Institution guidelines and coefficients of variation are presented in Table 7. The PA-start interval and the PA-peak interval, which mainly express atrial electrical function showed the largest inter- and intra-observer measurement errors and variability. However, the A-wave duration and the total electromechanical activity, which express a combination of the atrial electrical and mechanical functions, had better values of measurement error and repeatability. The same was true for all the TVE-derived variables that express regional and global atrial mechanical function.

\section{Discussion}

The main new findings of this study of healthy young individuals are as follows. (1) Some TVE-derived variables indirectly reflect the atrial electrical activation that follows the known activation process as revealed by invasive electrophysiology. (2) The regional and global atrial mechanical function is explained by an upward movement of the atrial walls at the region near the $\mathrm{A}-\mathrm{V}$ ring with 


\section{PA-start interval (P-Aa' start)}

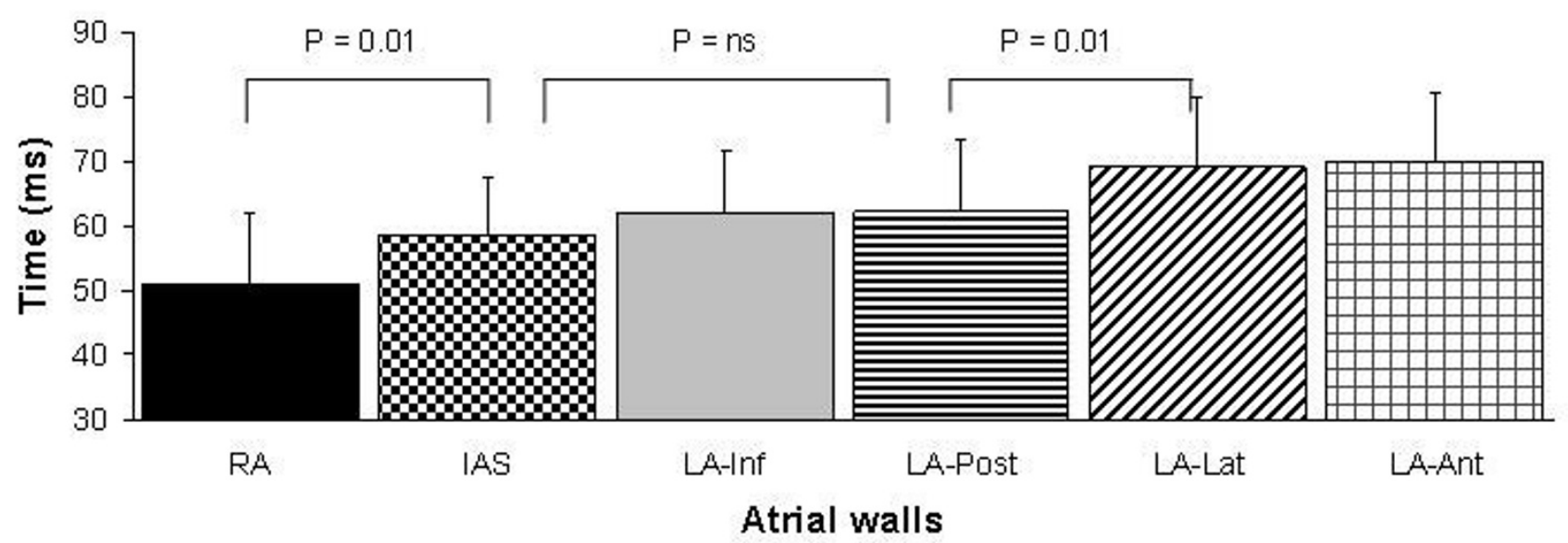

Figure 3

Assessment of the duration of the PA-start interval in all atrial walls. Comparisons were done with ANOVA with repeated measures and the Bonferroni's test.

a continuous reduction of this movement towards the upper levels of atrial walls. (3) The atrial mechanical function is quite similar in all LA walls; however, all indices of mechanical function were higher in the RA than in the LA. (4) There were no correlations between the 2-D- and TVEderived variables expressing atrial mechanical function. (5) Values of measurement error and repeatability were good for atrial mechanical function, but only acceptable for electrical function.

Atrial electrical activation, as assessed by the PA-start interval, began at the RA and followed through the IAS, to the inferior and posterior LA walls. This is the known normal electrical activation process, as obtained by invasive elec- trophysiology techniques.[32,37] In the present study, there were no statistical significant differences in the PAstart interval between IAS and the inferior and posterior LA walls, indicating that the activation process could indistinctly occur through any of these walls, as demonstrated by the presence of preferential conduction pathways nearby the IAS, the posterior LA wall and the coronary sinus.[33,34,37]. In a recent study, using M-mode color tissue Doppler registrations of the tricuspide and mitral rings, an abnormal time interval from the onset of $P$ wave until the backward motion of the left atrio-ventricular ring was used to indirectly detect abnormal atrial electromechanical coupling in patients with paroxysmal atrial fibrillation.[43] 


\section{PA-peak interval (P-Aa' peak)}

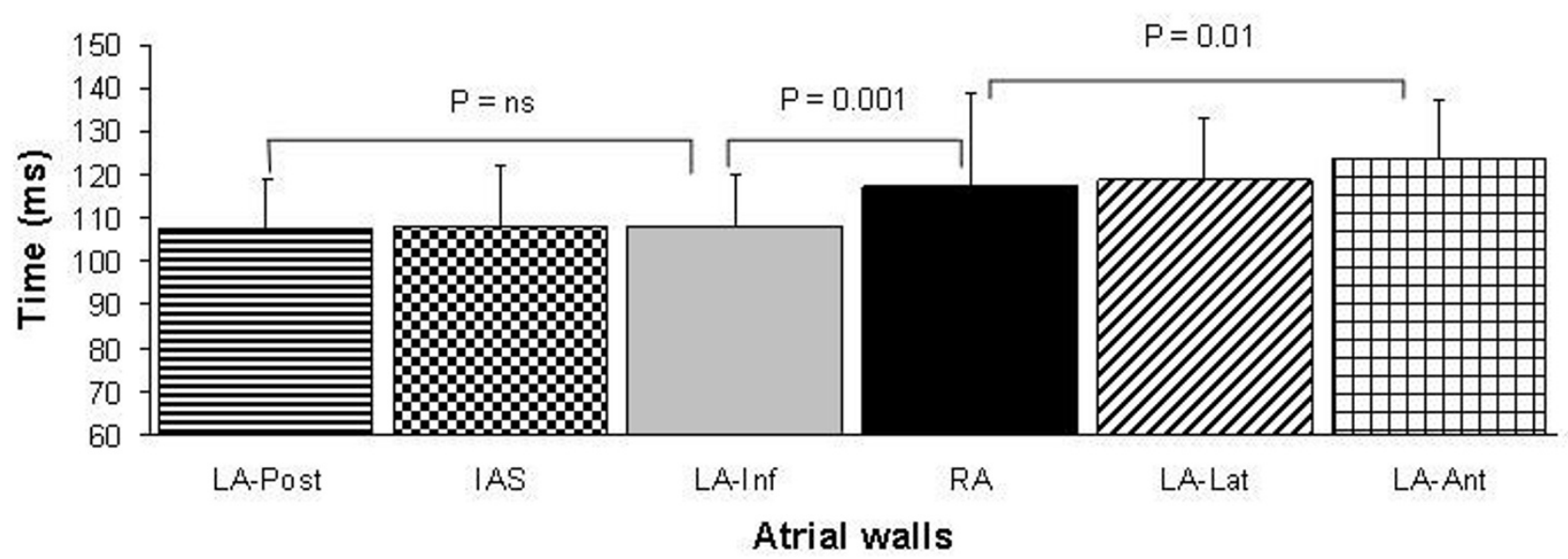

Figure 4

Assessment of the duration of the PA-peak interval in all atrial walls. Comparisons were done with ANOVA with repeated measures and the Bonferroni's test.

The relation between atrial anatomy and its mechanical function has been poorly studied. The present study showed that all atrial walls actively moved upwards from the region of the $\mathrm{A}-\mathrm{V}$ ring at late diastole, with a reduction of this movement towards the upper parts, thus empting the atria and contributing towards the last part of filling of the LV. This longitudinal movement of the atrial walls is probably related to the longitudinal endocardial muscular fibers along the walls of the LA and RA. The more pronounced longitudinal movement in the RA may be explained in part by the larger pectinate muscles in the RA, but also by the lower pressures in the heart's right side. To what extent circumferential contraction of the atrial muscle fibers might contribute to atrial mechanical function is unknown. Anatomically, the large amount of circumferential muscle fibers present in the vestibules of the RA and LA[30,31,44] might imply some kind of circumferential or radial contraction of the atria. However, no movement of the posterior LA wall at late diastole can be observed by conventional M-mode echocardiography. Other circumferential fibers, such as Bachman's bundle located at the subepicardium joining the RA and LA, seem to play a critical role for electrical impulse spreading[37] rather than in circumferential atrial contraction. The assessment of circumferential atrial mechanical function by conventional echocardiography and TVE remains elusive.

No correlations were found between 2-D- and TVEderived variables of atrial mechanical function, as was 
Table 4: Myocardial velocity and velocity-derived variables measured at right and left atrial myocardial walls.

\begin{tabular}{|c|c|c|c|c|c|c|c|c|}
\hline Variables & Level & $\mathbf{R A}$ & IAS & LA-Lat & LA-Inf & LA-Ant & LA-Post & $P *$ \\
\hline Aa' peak vel. & Low & $8.1 \pm 2.7$ & $6.3 \pm 1.4$ & $6.2 \pm 1.7$ & $6.9 \pm 1.8$ & $6.3 \pm 1.8$ & $6.8 \pm 1.8$ & NS \\
\hline \multirow{2}{*}{$(\mathrm{cm} / \mathrm{s})$} & Mid & $6.9 \pm 2.4$ & $5.2 \pm 1.5$ & $5.7 \pm 1.4$ & $5.1 \pm 1.7$ & $5.7 \pm 1.8$ & $5.4 \pm 1.7$ & NS \\
\hline & $P$ & $<0.001$ & $<0.001$ & $<0.001$ & $<0.001$ & $<0.01$ & $<0.001$ & \\
\hline Aa' disp. & Low & $6.7 \pm 2.3$ & $4.5 \pm 0.9$ & $3.7 \pm 1.0$ & $4.2 \pm 1.0$ & $4.1 \pm 1.2$ & $4.0 \pm 0.9$ & NS \\
\hline \multirow[t]{2}{*}{$(\mathrm{mm})$} & Mid & $5.8 \pm 2.5$ & $3.2 \pm 0.9$ & $3.4 \pm 0.9$ & $2.9 \pm 0.7$ & $3.1 \pm 1.3$ & $3.0 \pm 0.8$ & NS \\
\hline & $P$ & $<0.001$ & $<0.001$ & $<0.001$ & $<0.001$ & $<0.001$ & $<0.001$ & \\
\hline Aa' cont. & Low & $31 \pm 10$ & $33 \pm 8$ & $29 \pm 10$ & $28 \pm 7$ & $31 \pm 12$ & $26 \pm 6$ & NS \\
\hline \multirow[t]{2}{*}{ (\%) } & Mid & $27 \pm 11$ & $24 \pm 7$ & $25 \pm 9$ & $19 \pm 6$ & $23 \pm 11$ & $19 \pm 5$ & NS \\
\hline & $P$ & $<0.001$ & $<0.001$ & 0.02 & $<0.001$ & $<0.001$ & $<0.001$ & \\
\hline Aa' SR (s-') & & $-4.9 \pm 0.8$ & $-2.7 \pm 0.7$ & $-3.7 \pm 0.9$ & $-3.2 \pm 0.8$ & $-3.3 \pm 1.0$ & $-3.7 \pm 1.0$ & 0.001 \\
\hline$A a^{\prime} S(\%)$ & & $29 \pm 7$ & $14 \pm 5$ & $15 \pm 4$ & $16 \pm 5$ & $15 \pm 6$ & $16 \pm 4$ & NS \\
\hline
\end{tabular}

Abbreviations: Aa' cont., atrial contribution; Aa' disp., atrial displacement; Aa' peak vel., atrial A-wave peak velocity; Aa' S, atrial strain; Aa' SR, atrial strain rate: $\mathbf{P}$, paired $t$ test; $\boldsymbol{P}^{*}$, analysis of variance; otherwise as in Table $3 \mathrm{a}$.

Aa' peak vel Low: RA vs IAS, LA-Lat and LA-Ant $(P<0.001)$. No differences were found between any LA walls.

Aa' peak vel Mid: RA vs IAS, LA-Inf, LA-Post and LA-Ant $(P<0.00 I)$. No differences were found between any LA walls.

Aa' disp. Low and Mid: RA vs all walls $(P<0.001)$. No differences were found between any LA-walls.

Aa' cont. Low and Mid: No differences were found between walls

Aa' SR: RA vs all LA walls $(P<0.00 I)$, IAS vs LA-Lat and LA-Post $(P<0.00$ I $)$

Aa' S: RA vs all LA walls $(P<0.00 I)$. No differences were found between any LA walls.

Table 5: Correlation coefficients between 2-D- and TVE-derived variables of left global atrial mechanical function. Individual values of the inter-atrial septum, and the inferior, anterior, lateral and posterior LA walls were averaged.

\begin{tabular}{lcccc}
\hline & LA-Aa' peak vel. & LA-Aa' disp. & LA-Aa' cont. & LA-Aa' SR \\
\hline LA-Diameter & 0.33 & $0.57^{*}$ & 0.43 & 0.2 \\
LA-Long axis & 0.00 & 0.17 & 0.02 & -0.21 \\
LA-Short axis & -0.2 & 0.02 & -0.08 & -0.16 \\
LA-Area & -0.12 & 0.01 & -0.13 & -0.12 \\
LA-P-wave volume & -0.15 & 0.02 & -0.08 & -0.14 \\
LA-Maximal volume & 0.07 & 0.05 & -0.1 & -0.03 \\
LA-Minimal volume & 0.2 & 0.15 & -0.13 & -0.13 \\
LA-Ejection fraction & -0.27 & -0.23 & -0.31 & -0.21 \\
LA-Active emptying & -0.35 & -0.22 & -0.31 & -0.03 \\
\end{tabular}

Abbreviations: LA. Left atria; otherwise as in Table 3. $* P<0.01$

also found in a previous study[29]. Although 2-D-derived variables measure volumes and volume-derived indices that might indicate some kind of atrial mechanical force, it was surprising to find no correlations between the variables obtained by the two different techniques. This might indicate that the velocities and the displacements registered from all atrial walls by TVE are less dependent on volume loading conditions than 2 -D-derived variables and therefore could be used as reliable measurement of pure atrial mechanical contraction or inotropism. In fact, Donald et al. showed that LA function assessed by TVE was relatively independent of LV function.[45] It should also be considered that movements of the heart not related to atrial contraction might partly contribute to the velocities and displacements registered from all atrial walls. Therefore, 2-D- and TVE-derived variables might not be used interchangeably to assess atrial mechanical function.

Some measures of atrial electrical function, for example the PA-start interval and the PA-peak interval, had only fair measures of repeatability and measurement error. However, most of the TVE-derived variables expressing atrial mechanical function had good values of repeatability and measurement error. Assessing atrial mechanical function by measuring volumes is time-consuming and depends on age, gender, and body surface area $[14,19]$ In addition, atrial volume indices are also dependent on loading conditions [46,47] and are not necessarily more reproducible than TVE-derived variables. 
Table 6: Correlation coefficients between 2-D- and TVE-derived variables of right global atrial mechanical function. Individual values of the inter-atrial septum, and the inferior, anterior, lateral and posterior LA walls were averaged.

\begin{tabular}{lccccc}
\hline & RA-Aa' peak vel. & RA-Aa' disp. & RA-Aa' cont. & RA-Aa' SR & RA-Aa' S \\
\hline RA-Long axis & 0.35 & $0.58^{*}$ & 0.53 & 0.26 & -0.07 \\
RA-Short axis & 0.06 & 0.30 & 0.20 & -0.00 & $-0,14$ \\
RA-Area & 0.10 & 0.31 & 0.20 & -0.00 & -0.14 \\
RA-P-wave volume & 0.09 & 0.31 & 0.21 & 0.08 & -0.15 \\
RA-Maximal volume & -0.06 & 0.16 & 0.12 & -0.04 & -0.26 \\
RA-Minimal volume & 0.10 & 0.24 & 0.25 & $-\left.0.4\right|^{*}$ & -0.18 \\
RA-Ejection fraction & -0.33 & -0.24 & -0.35 & -0.08 & -0.08 \\
RA-Active emptying & 0.07 & 0.27 & 0.12 &
\end{tabular}

Abbreviations: RA, right atrial; otherwise as in Table 3. $* P<0.0$ I

Table 7: Assessment of inter- and intra-observer measurement error and repeatability according to the British Standards Institution guidelines and coefficients of variation

\begin{tabular}{lcccc}
\hline & Inter-observer & & Intra-observer \\
\hline Variable & BSI & CV (\%) & BSI & CV (\%) \\
\hline P-Aa' start, ms & 37 & 24 & 28 & 19 \\
P-Aa' peak, ms & 51 & 16 & 47 & 14 \\
Aa' duration, $\mathbf{m s}$ & 32 & 8.8 & 25 & 7.5 \\
TEMA, ms & 53 & 9.7 & 45 & 8.2 \\
Aa' peak velocity, $\mathbf{c m} / \mathbf{s}$ & 2.14 & 10.1 & 1.78 & 8.7 \\
Aa' displacement, $\mathbf{m m}$ & 1.81 & 12.3 & 1.77 & 1.8 \\
Aa' SR & -0.79 & 9.4 & -0.71 & 7.8 \\
Aa' S, \% & 5.4 & 9.6 & 4.5 & 9.1 \\
LA maximal volume, $\mathbf{m L}$ & 22 & 18.4 & 18 & 14.7 \\
\hline
\end{tabular}

Abbreviations: BSI, British Standards Institution; CV, coefficient of variation; otherwise as in Table 3.

\section{Possible clinical implications}

The identification of an abnormal electrical activation process could be of interest in some patients with atrial fibrillation or other supra-ventricular tachy-arrhythmias, in whom the premature atrial contraction acting as a triggering factor could be aggravated by local delayed conduction (reviewed in $[48,49]$ ). Further refinement of the TVE technique are necessary not only to identify the mechanical activation atrial sequence during normal sinus rhythm, but also to identify the origin and the activation sequence of supra-ventricular ectopic beats and in patients with RA, IAS or bi-atrial pacing. Thus, TVE could be an excellent adjunct to invasive electrophysiological techniques in selecting adequate patients and in the evaluation of atrial electromechanical consequences of RA, IAS or bi-atrial pacing.

The assessment of pure mechanical atrial function by means of atrial wall movements may give more concrete clues about the recovery process of atrial electromechanical function after conversion for atrial fibrillation and flut- ter and can give additional pathophysiological insights on the thromboembolic process that occur in some of those patients.[50] TVE-derived parameters may also give additional pathophysiological information on the process of atrial electromechanical remodeling that occurs in patients with sustained supra-ventricular tachy-arrhythmias.[51]

Several studies have shown the independent prognostic value of atrial function measurements in subsets of patients. $[6,11,12]$ TVE-derived variables of atrial mechanical function may have an additional role for facilitating the assessment of atrial function and consequently in the process of risk stratification.

\section{Study limitations}

The results of the present study refer only to a group of young healthy individuals and the values for each of the studied variables are, therefore, only applicable to that population group. As discussed, the measures of atrial electrical function showed only fair values of repeatability 
and measurement error. There were two reasons: the image acquisition rate (less than 100 frames per second) means an implicit measurement error of $10 \mathrm{~ms}$; it was also difficult to identify the beginning of the P-wave in the ECG from the monitor in the echocardiography machine. Improving temporal resolution by image acquisition at more than 200 frames per second, and improving and adjusting the ECG quality in the present equipment may help solve or decrease this problem. The velocities and displacements registered by atrial walls do not only represent the process of atrial contraction, but also the translational movement of the heart. Until now, no appropriate algorithms that correctly deal with this problem have been found. Presently, it is not possible by means of TVE to simultaneously record the electromechanical function of all atrial walls in one heartbeat. The development of three-dimensional TVE may help resolve this difficulty.

\section{Conclusion}

TVE is a noninvasive bedside tool that requires further refinements to provide reproducible, repeatable and potentially clinically useful data on atrial electromechanical function in health and disease.

\section{References}

I. Henry WL, Morganroth J, Pearlman AS, Clark CE, Redwood DR, Itscoitz SB, Epstein SE: Relation between echocardiographically determined left atrial size and atrial fibrillation. Circulation 1976, 53:273-9.

2. Vaziri SM, Larson MG, Benjamin EJ, Levy D: Echocardiographic predictors of nonrheumatic atrial fibrillation. The Framingham Heart Study. Circulation 1994, 89:724-30.

3. Benjamin EJ, D'Agostino RB, Belanger AJ, Wolf PA, Levy D: Left atrial size and the risk of stroke and death. The Framingham Heart Study. Circulation 1995, 92:835-4I.

4. Predictors of thromboembolism in atrial fibrillation: II. Echocardiographic features of patients at risk. The Stroke Prevention in Atrial Fibrillation Investigators. Ann Intern Med 1992, 116:6-12.

5. Mattioli AV, Tarabini Castellani E, Mattioli G: Stroke in paced patients with sick sinus syndrome: influence of left atrial function and size. Cardiology 1999, 91 I: I50-5.

6. Tsang TS, Barnes ME, Gersh BJ, Takemoto Y, Rosales AG, Bailey KR, Seward JB: Prediction of risk for first age-related cardiovascular events in an elderly population: the incremental value of echocardiography. J Am Coll Cardiol 2003, 42: I 199-205.

7. Jikuhara T, Sumimoto T, Tarumi N, Yuasa F, Hattori T, Sugiura T, Iwasaka $\mathrm{T}$ : Left atrial function as a reliable predictor of exercise capacity in patients with recent myocardial infarction. Chest 1997, III:922-8.

8. Paraskevaidis IA, Dodouras T, Adamopoulos S, Kremastinos DT: Left atrial functional reserve in patients with nonischemic dilated cardiomyopathy: an echocardiographic dobutamine study. Chest 2002, I 22:1340-7.

9. Triposkiadis F, Moyssakis I, Hadjinikolaou L, Makris T, Zioris H, Hatzizaharias A, Kyriakidis $M$ : Left atrial systolic function is depressed in idiopathic and preserved in ischemic dilated cardiomyopathy. Eur J Clin Invest 1999, 29:905-12.

10. Modena MG, Muia N, Sgura FA, Molinari R, Castella A, Rossi R: Left atrial size is the major predictor of cardiac death and overall clinical outcome in patients with dilated cardiomyopathy: a long-term follow-up study. Clin Cardiol 1997, 20:553-60.

1I. Beinart R, Boyko V, Schwammenthal E, Kuperstein R, Sagie A, Hod H, Matetzky S, Behar S, Eldar M, Feinberg MS: Long-term prognostic significance of left atrial volume in acute myocardial infarction. J Am Coll Cardiol 2004, 44:327-34.
12. Moller JE, Hillis GS, Oh JK, Seward JB, Reeder GS, Wright RS, Park SW, Bailey KR, Pellikka PA: Left atrial volume: a powerful predictor of survival after acute myocardial infarction. Circulation 2003, I 07:2207-I2.

13. Lester SJ, Ryan EW, Schiller NB, Foster E: Best method in clinical practice and in research studies to determine left atrial size. Am J Cardiol 1999, 84:829-32.

14. Pritchett AM, Jacobsen SJ, Mahoney DW, Rodeheffer RJ, Bailey KR, Redfield MM: Left atrial volume as an index of left atrial size: a population-based study. J Am Coll Cardiol 2003, 41:1036-43.

15. Payne RM, Stone HL, Engelken EJ: Atrial function during volume loading. J Appl Physiol I97I, 31:326-31.

16. Hitch DC, Nolan SP: Descriptive analysis of instantaneous left atrial volume - with special reference to left atrial function. J Surg Res 1981, 30:110-20.

17. Tsang TS, Barnes ME, Gersh BJ, Bailey KR, Seward JB: Left atrial volume as a morphophysiologic expression of left ventricular diastolic dysfunction and relation to cardiovascular risk burden. Am J Cardiol 2002, 90: 1284-9.

18. Prioli A, Marino P, Lanzoni L, Zardini P: Increasing degrees of left ventricular filling impairment modulate left atrial function in humans. Am J Cardiol 1998, 82:756-61.

19. Nikitin NP, Witte KK, Thackray SD, Goodge LJ, Clark AL, Cleland JG: Effect of age and sex on left atrial morphology and function. Eur J Echocardiogr 2003, 4:36-42.

20. Manning WJ, Silverman DI, Katz SE, Riley MF, Come PC, Doherty RM, Munson JT, Douglas PS: Impaired left atrial mechanical function after cardioversion: relation to the duration of atrial fibrillation. J Am Coll Cardiol 1994, 23:1535-40.

21. Mattioli AV, Castelli A, Andria A, Mattioli G: Clinical and echocardiographic features influencing recovery of atrial function after cardioversion of atrial fibrillation. Am J Cardiol 1998, 82:|368-7|.

22. Jones C], Song G], Gibson DG: An echocardiographic assessment of atrial mechanical behaviour. Br Heart J 1991, 65:31-6.

23. Nishimura RA, Tajik AJ: Evaluation of diastolic filling of left ventricle in health and disease: Doppler echocardiography is the clinician's Rosetta Stone. J Am Coll Cardiol 1997, 30:8-18.

24. Oh JK, Appleton CP, Hatle LK, Nishimura RA, Seward JB, Tajik AJ: The noninvasive assessment of left ventricular diastolic function with two-dimensional and Doppler echocardiography. J Am Soc Echocardiogr 1997, 10:246-70.

25. Garcia MJ, Thomas JD, Klein AL: New Doppler echocardiographic applications for the study of diastolic function. J Am Coll Cardiol 1998, 32:865-75.

26. Wilkenshoff UM, Sovany A, Wigstrom L, Olstad B, Lindstrom L, Engvall J, Janerot-Sjoberg B, Wranne B, Hatle L, Sutherland GR: Regional mean systolic myocardial velocity estimation by real-time color Doppler myocardial imaging: a new technique for quantifying regional systolic function. J Am Soc Echocardiogr 1998, I 1 :683-92.

27. Kukulski T, Jamal F, D'Hooge J, Bijnens B, De Scheerder I, Sutherland GR: Acute changes in systolic and diastolic events during clinical coronary angioplasty: a comparison of regional velocity, strain rate, and strain measurement. J Am Soc Echocardiogr 2002, 15:1-12.

28. Hesse B, Schuele SU, Thamilasaran M, Thomas J, Rodriguez L: A rapid method to quantify left atrial contractile function: Doppler tissue imaging of the mitral annulus during atrial systole. Eur J Echocardiogr 2004, 5:86-92.

29. Thomas L, Levett K, Boyd A, Leung DY, Schiller NB, Ross DL: Changes in regional left atrial function with aging: evaluation by Doppler tissue imaging. Eur J Echocardiogr 2003, 4:92-100.

30. Wang K, Ho SY, Gibson DG, Anderson RH: Architecture of atrial musculature in humans. Br Heart J 1995, 73:559-65.

31. Ho SY, Anderson RH, Sanchez-Quintana D: Atrial structure and fibres: morphologic bases of atrial conduction. Cardiovasc Res 2002, 54:325-36.

32. Markides V, Schilling RJ, Ho SY, Chow AW, Davies DW, Peters NS: Characterization of left atrial activation in the intact human heart. Circulation 2003, 107:733-9.

33. Antz M, Otomo K, Arruda M, Scherlag BJ, Pitha J, Tondo C, Lazzara $\mathrm{R}$, Jackman WM: Electrical conduction between the right atrium and the left atrium via the musculature of the coronary sinus. Circulation 1998, 98: 1790-5. 
34. Chauvin M, Shah DC, Haissaguerre M, Marcellin L, Brechenmacher C: The anatomic basis of connections between the coronary sinus musculature and the left atrium in humans. Circulation 2000, I 01:647-52

35. Gepstein L, Hayam G, Ben-Haim SA: A novel method for nonfluoroscopic catheter-based electroanatomical mapping of the heart. In vitro and in vivo accuracy results. Circulation 1997, 95: $161 \mid-22$.

36. Smeets JL, Ben-Haim SA, Rodriguez LM, Timmermans C, Wellens HJ: New method for nonfluoroscopic endocardial mapping in humans: accuracy assessment and first clinical results. Circulation 1998, 97:2426-32.

37. Roithinger FX, Cheng J, SippensGroenewegen A, Lee RJ, Saxon LA, Scheinman MM, Lesh MD: Use of electroanatomic mapping to delineate transseptal atrial conduction in humans. Circulation 1999, 100:1791-7.

38. Haissaguerre M, Jais P, Shah DC, Takahashi A, Hocini M, Quiniou G, Garrigue S, Le Mouroux A, Le Metayer P, Clementy J: Spontaneous initiation of atrial fibrillation by ectopic beats originating in the pulmonary veins. N Engl ] Med 1998, 339:659-66.

39. Cosio FG, Lopez-Gil M, Goicolea A, Arribas F, Barroso JL: Radiofrequency ablation of the inferior vena cava-tricuspid valve isthmus in common atrial flutter. Am / Cardiol 1993, 7 I:705-9.

40. Oral H, Knight BP, Tada H, Ozaydin M, Chugh A, Hassan S, Scharf C, Lai SW, Greenstein R, Pelosi FJr, Strickberger SA, Morady F: Pulmonary vein isolation for paroxysmal and persistent atrial fibrillation. Circulation 2002, I 05:1077-8I.

4I. Schiller NB, Shah PM, Crawford M, DeMaria A, Devereux R, Feigenbaum H, Gutgesell H, Reichek N, Sahn D, Schnittger I, et al.: Recommendations for quantitation of the left ventricle by twodimensional echocardiography. American Society of Echocardiography Committee on Standards, Subcommittee on Quantitation of Two-Dimensional Echocardiograms. J Am Soc Echocardiogr 1989, 2:358-67.

42. Kircher B, Abbott JA, Pau S, Gould RG, Himelman RB, Higgins CB, Lipton MJ, Schiller NB: Left atrial volume determination by biplane two-dimensional echocardiography: validation by cine computed tomography. Am Heart J I99I, I 2 I:864-7I

43. Omi W, Nagai $H$, Takamura M, Okura S, Okajima M, Furusho $H$, Maruyama M, Sakagami S, Takata S, Kaneko S: Doppler tissue analysis of atrial electromechanical coupling in paroxysmal atrial fibrillation. J Am Soc Echocardiogr 2005, I 8:39-44.

44. Ho SY, Sanchez-Quintana D, Cabrera JA, Anderson RH: Anatomy of the left atrium: implications for radiofrequency ablation of atrial fibrillation. J Cardiovasc Electrophysiol 1999, I 0:1525-33.

45. Donal E, Raud-Raynier P, Racaud A, Coisne D, Herpin D: Quantitative regional analysis of left atrial function by Doppler tissue imaging-derived parameters discriminates patients with posterior and anterior myocardial infarction. $J A m$ Soc Echocardiogr 2005, I 8:32-8.

46. Appleton CP, Galloway JM, Gonzalez MS, Gaballa M, Basnight MA Estimation of left ventricular filling pressures using twodimensional and Doppler echocardiography in adult patients with cardiac disease. Additional value of analyzing left atrial size, left atrial ejection fraction and the difference in duration of pulmonary venous and mitral flow velocity at atrial contraction. J Am Coll Cardiol 1993, 22:1972-82.

47. Simek CL, Feldman MD, Haber HL, Wu CC, Jayaweera AR, Kaul S: Relationship between left ventricular wall thickness and left atrial size: comparison with other measures of diastolic function. J Am Soc Echocardiogr 1995, 8:37-47.

48. Waldo AL: Mechanisms of atrial flutter and atrial fibrillation: distinct entities or two sides of a coin? Cardiovasc Res 2002 54:217-29.

49. Nattel S: Therapeutic implications of atrial fibrillation mechanisms: can mechanistic insights be used to improve AF management? Cardiovasc Res 2002, 54:347-60.

50. Sparks PB, Jayaprakash S, Mond HG, Vohra JK, Grigg LE, Kalman JM: Left atrial mechanical function after brief duration atrial fibrillation. I Am Coll Cardiol 1999, 33:342-9.

51. Zipes DP: Atrial fibrillation. A tachycardia-induced atrial cardiomyopathy. Circulation 1997, 95:562-4.

\section{Publish with Biomed Central and every} scientist can read your work free of charge

"BioMed Central will be the most significant development for disseminating the results of biomedical research in our lifetime. "

Sir Paul Nurse, Cancer Research UK

Your research papers will be:

- available free of charge to the entire biomedical community

- peer reviewed and published immediately upon acceptance

- cited in PubMed and archived on PubMed Central

- yours - you keep the copyright 